\title{
Entrapment of the Median Nerve by a Muscular Branch of the Brachial Artery: A Case Report
}

\author{
Snehlata P. Samberkar1, Normadiah M. Kassim"1, Siti Rosmani M. Zin', \\ Prashant Samberkar ${ }^{2}$ \\ ${ }^{1}$ Department of Anatomy, Faculty of Medicine, University of Malaya, Kuala Lumpur, Malaysia \\ ${ }^{2}$ Department of Forensic Medicine and Pathology, Faculty of Medicine, University of Malaya, Kuala Lumpur, \\ Malaysia \\ Email: snehlata@um.edu.my
}

Received 16 April 2014; revised 4 June 2014; accepted 25 June 2014

Copyright (C) 2014 by authors and Scientific Research Publishing Inc.

This work is licensed under the Creative Commons Attribution International License (CC BY). http://creativecommons.org/licenses/by/4.0/

(c) (i) Open Access

\begin{abstract}
Variations in the arterial pattern of the upper limbs are commonly encountered in routine dissection. In-depth information of the vascular structure of the upper extremities is not only important for diagnostic interventions and surgical approaches, but has medico-legal implications. We report the unusual variation of an additional muscular branch of the brachial artery entrapping the median nerve in the middle of the arm. This anomaly was present in both upper extremities of an adult male Indo-Malaysian cadaver. The abnormality reported here might result in neurovascular compression symptoms in the upper limbs. Knowledge of the vascular dissimilarity of the brachial artery and its division, and possible neurovascular entrapment is important to surgeons and medical practitioners for anticipating nerve compression and for confirmation via motor and sensory examination.
\end{abstract}

Keywords

Anatomical Variation, Brachial Artery, Median Nerve, Bilateral Upper Extremity, Trapped Nerve

\section{Introduction}

The brachial artery is a continuation of the third part of the axillary artery and is superficial throughout its course in the arm. At the cubital fossa, the bicipital aponeurosis, which separates the artery from the median cubital 
vein, crosses it superficially. The brachial artery terminates by dividing into the radial and ulnar arteries at the level of the neck of the radius. In the arm, it gives rise to muscular branches to the muscles of the arm, nutrient artery to the humerus, profundabrachii artery, and superior and inferior ulnar collateral arteries.

The median nerve is formed by medial and lateral roots from the medial and lateral cords of the brachial plexus respectively, and runs down the arm from the axilla at the inferior margin of the teres major muscle. Subsequently, it descends along the lateral side of the third part of the axillary artery and the proximal part of the brachial artery. In the middle of the arm, opposite the coracobrachialis insertion, the nerve crosses tangentially in front of the artery and runs along the medial side of the brachial artery. It subsequently appears in the cubital fossa beneath the bicipital aponeurosis and rests on the brachialis. The nerve exits the cubital fossa through a gap between the superficial and deep heads of the pronator teres [1].

\section{Case Report}

The present study involved the dissection of both upper limbs of a 55-year-old male Indo-Malaysian cadaver at the Anatomy Department of the University Malaya, Malaysia.

Exploration of the upper limbs was carried out according to the instructions in A New Approach to Dissection of the Human Body [2]. We used the axilla as the landmark and then dissected the anterior compartment of the arm to expose the course, distribution, and termination of the brachial artery and median nerve. The dissected area was rinsed with water and photographs were taken using a Nikon DSLR D3100. During the dissection, we found an additional muscular branch of the brachial artery entrapping the median nerve in the center of the arm (Figure 1). This anomaly was present in both upper extremities.

Right arm: At $143.41 \mathrm{~mm}$ away from the coracoid process, we observed that the muscular branch of the brachial artery wound closely over the median nerve (Figure 2). The distance between the muscular branch and elbow joint was $143.41 \mathrm{~mm}$, which confirmed the location of muscular artery as being exactly at the center of the arm. The muscular branch supplied the biceps brachii muscle (Figure 3). The length and diameter of the muscular branch were $17.57 \mathrm{~mm}$ and $3.49 \mathrm{~mm}$, respectively. We calculated that the diameter of the brachial artery was $6.24 \mathrm{~mm}$. We noted that the terminal branches of the brachial artery were $36 \mathrm{~mm}$ away from the trochlear process of the humerus, and confirmed it based on its location in the cubital fossa.

Left arm: At $63.40 \mathrm{~mm}$ from the coracoid process, we observed that the muscular branch of the brachial artery wound closely over the median nerve (Figure 4). The length and diameter of the muscular branch were 52.18 $\mathrm{mm}$ and $3.21 \mathrm{~mm}$, respectively. We calculated that the diameter of the brachial artery was $7.54 \mathrm{~mm}$.

After comparing both upper limbs, we documented the presence of the muscular branch of the brachial artery in both arms winding over the median nerve (Figure 5), but the origin of the muscular artery was much higher

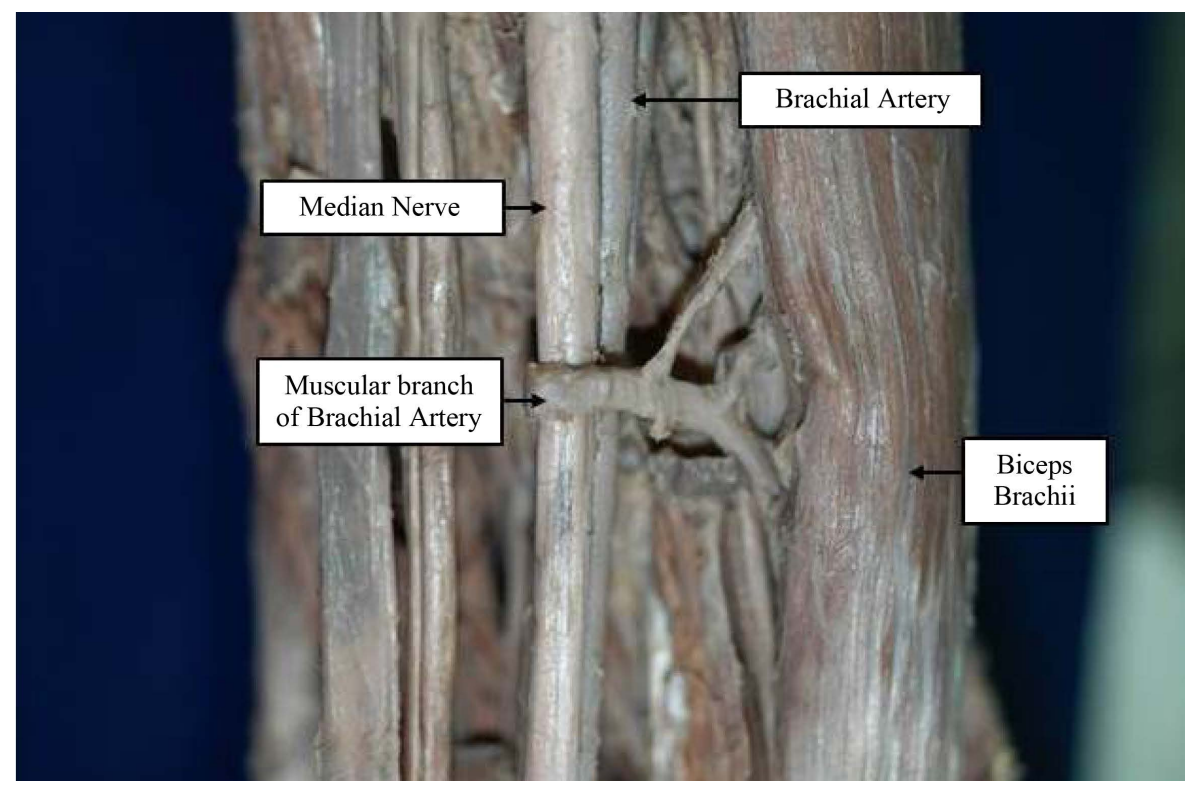

Figure 1. Entrapment of the median nerve by the muscular branch of the right brachial artery. 


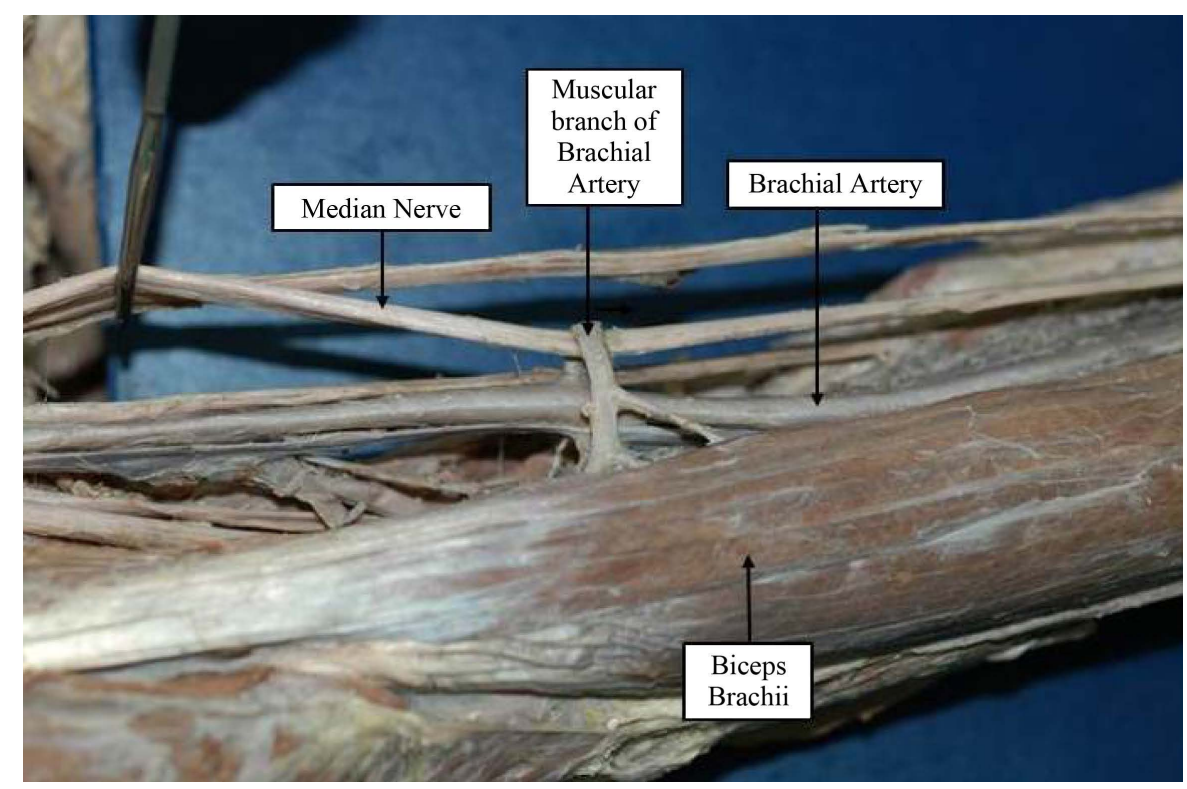

Figure 2. Muscular branch of the right brachial artery encompassing the median nerve.

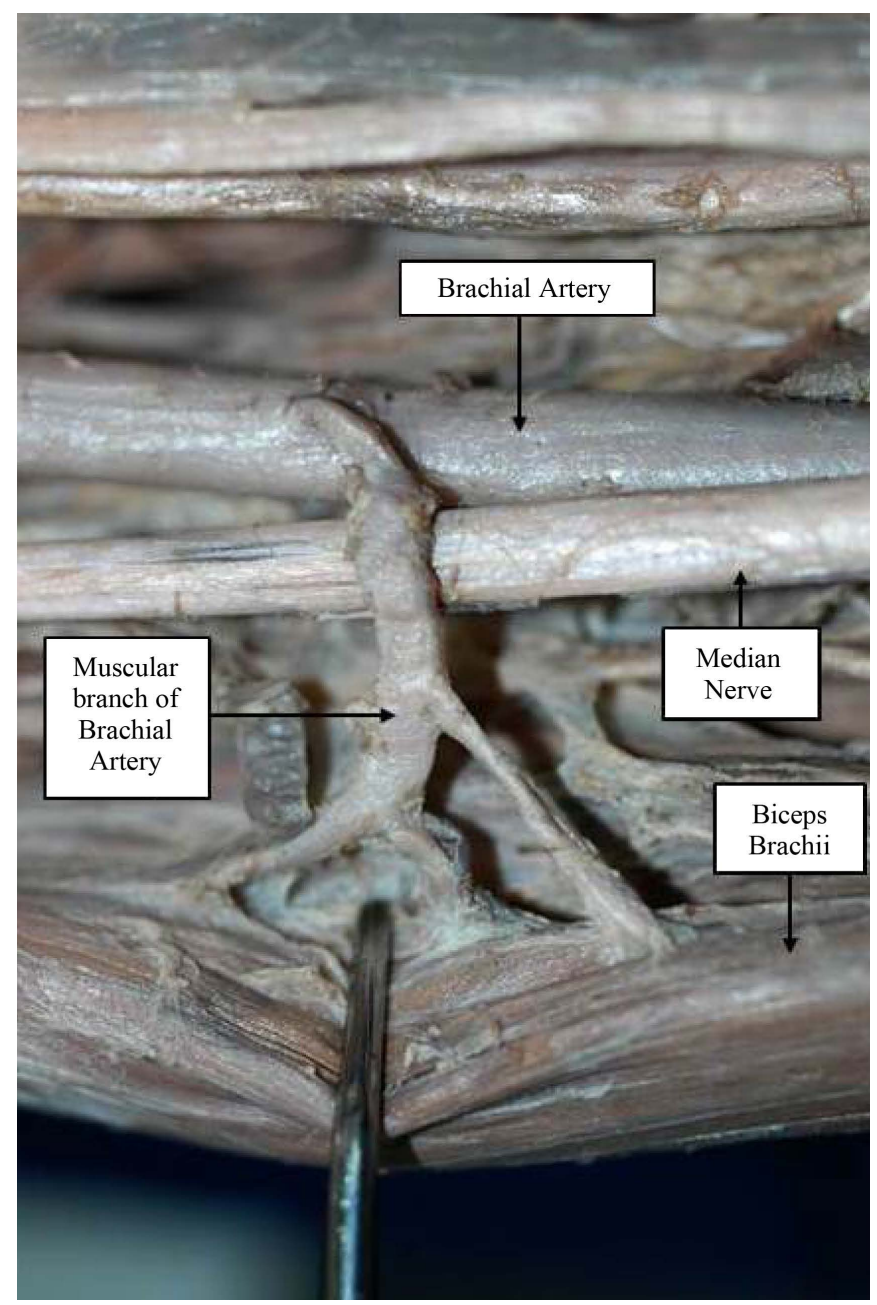

Figure 3. The muscular branch supplying the biceps brachii muscle of the right arm. 


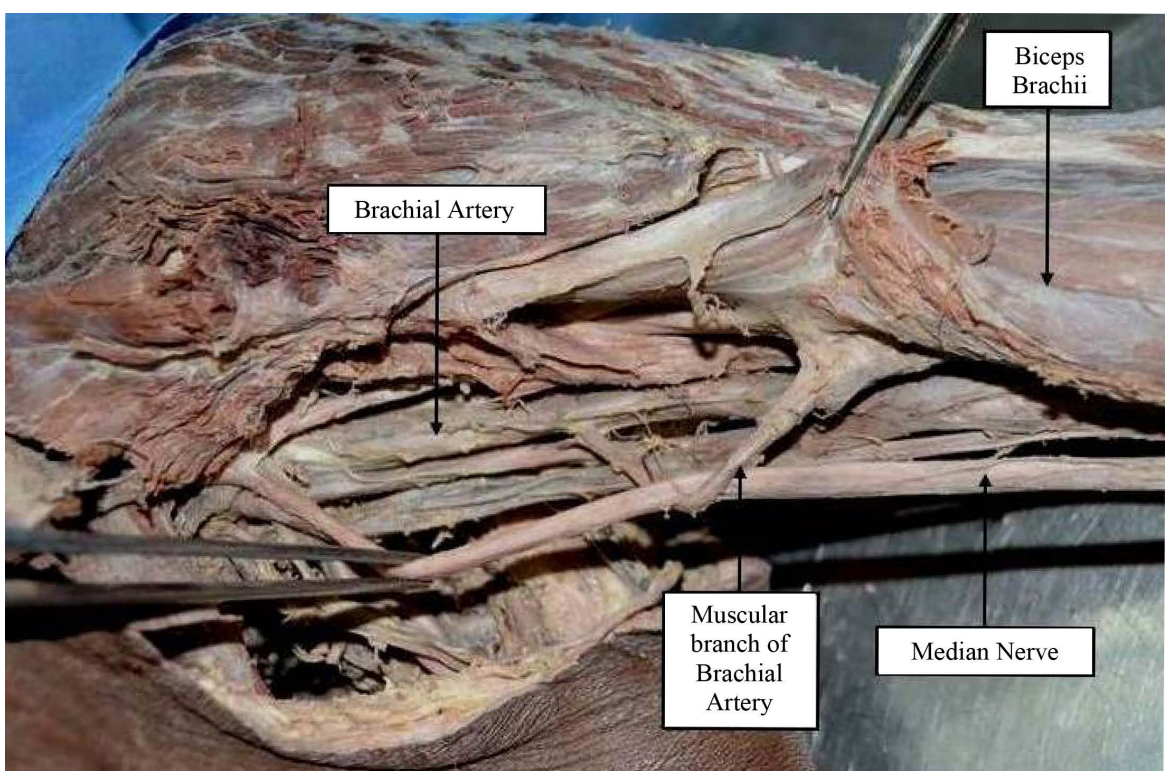

Figure 4. Entrapment of the median nerve by the muscular branch of the left brachial artery.

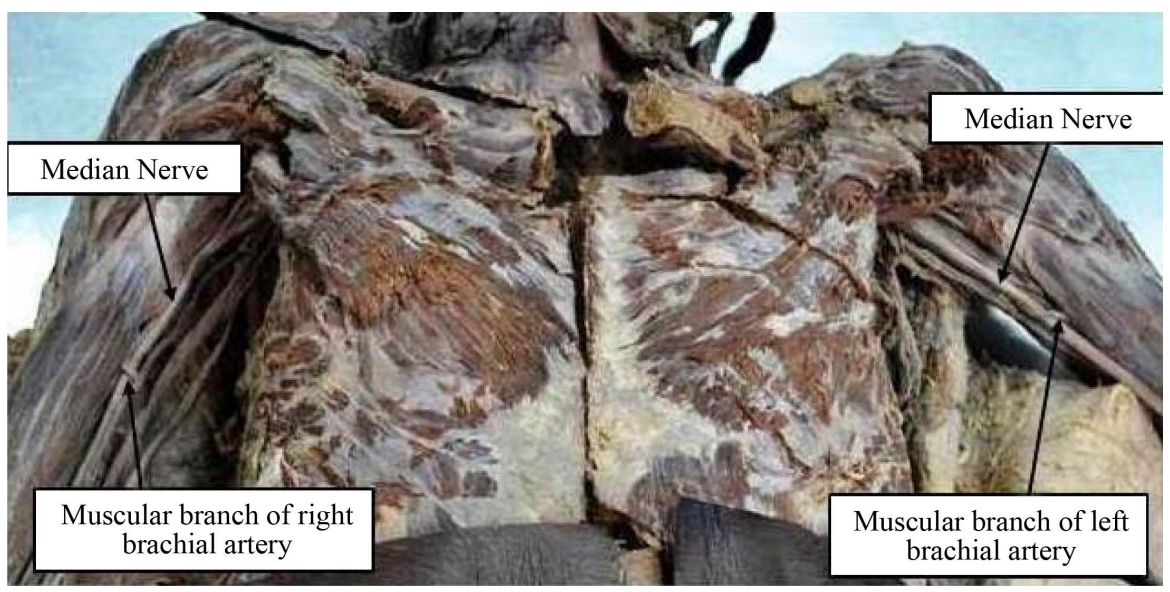

Figure 5. The muscular branches of the right and left brachial arteries looping over the median nerves of the right and left arms, respectively.

on the left arm compared to the right. The muscular branch was relatively long and oblique on the left arm compared to the right.

\section{Discussion}

There are three well-defined entrapment syndromes involving the median nerve or its branches: carpal tunnel syndrome, pronator syndrome [3], and anterior interosseous syndrome [4]. Retrospective studies have documented variations in the brachial artery and its branches but we observed an entrapped median nerve.

In rare cases, the brachial artery may be absent [5], branch at a higher level [6], or trifurcate [7], [8], [9]. Baral et al. reported multiple arterial anomalies [10]. A case of an accessory brachial artery has also been reported [11]. Kumar et al. reported a high median nerve compression involving the brachial artery as being due to lacertus fibrosus [12]. Rodrigues et al. reported median nerve and brachial artery entrapment by the tendinous arch of the coracobrachialis muscle [13]. Additionally, the third head of the biceps brachii can cause median nerve entrapment [14] [15]. One clinical report noted a variation in the brachial artery while conducting transradial cardiac catheterization. The authors believed that the defect in brachial artery formation could have occurred during Singer stage V embryological arterial development of the upper extremities [16]. 
The present case differs from previously published reports because there is an additional muscular artery supplying the biceps brachii as it winds over the median nerve, which might result in neurovascular compression in the form of sensory and motor loss in the forearm and hand. During strenuous exercise, the median nerve might be entrapped, which might result in loss of sensation on the lateral part of the palm, the palmar surface of thumb, and the lateral two and one-half digits. The median nerve supplies no muscles in the arm; thus, they are not affected. However, pronation of the forearm, flexion of the wrist and digits, and important thumb movements might be severely affected.

Vascular and nerve entrapment symptoms can be treated easily once the source of the neurovascular entrapment is identified. Therefore, awareness of the variations of arterial patterns and nerve pathways will guide surgeons and clinicians in anticipating the related symptoms for further management.

\section{Acknowledgements}

We would like to acknowledge the support staff of the Anatomy Department, Faculty of Medicine, University of Malaya for the continual support rendered this case.

\section{References}

[1] Richard, S. (2008) Clinical Anatomy by Regions. Lippincott Williams \&Wilkins, Philadelphia.

[2] Kanagasuntheram, R., Krishnamurti, A. and Sivanandasingham, P. (1980) A New Approach to Dissection of the Human Body. 2nd Edition, Singapore University Press, Singapore City.

[3] Whitney, L. (2007) Pronator Teres Syndrome. Vol. 07 (5). Retrieved from Massage Today Website. http://www.massagetoday.com/mpacms/mt/article.php?id=13625

[4] George, M.B. and Nayak, B.S. (2008) Median Nerve and Brachial Artery Entrapment in the Abnormal Brachialis Muscle-A Case Report. Neuroanatomy, 7, 41-42.

[5] Ciervo, A., Kahn, M. and Pangilinan, A.J. (2001) Absence of the Brachial Artery: Report of A Rare Human Variation and Review of Upper Extremity Artery Anomalies. Journal of Vascular Surgery, 33, 191-194. http://dx.doi.org/10.1067/mva.2001.112212

[6] Standring, S. (2005) Grays Anatomy. Elsevier Churchill Livingstone, Edinburgh.

[7] Malcic, G.J., Gurunluoglu, R., Ozdogmus, O. and Yalin, A. (2002) Unique Case of Trifurcation of the Brachial Artery: Its Clinical Significance. Clinical Anatomy, 15, 224-227. http://dx.doi.org/10.1002/ca.10005

[8] Yalcin, B., Kocabiyik, N., Yazar, F., Kirici, Y. and Ozan, H. (2006) Arterial Variations of the Upper Extremities. Anatomical Science International, 81, 62-64. http://dx.doi.org/10.1111/j.1447-073X.2006.00110.x

[9] Vollala, R.V., Nagabhooshana, S. and Bhatt, M.S. (2008) Trifurcation of Brachial Artery with Variant Course of Radial Artery: Rare Observation. Anatomical Science International, 83, 307-309. http://dx.doi.org/10.1111/j.1447-073X.2008.00235.X

[10] Baral, P., Vijayabhaskar, P., Roy, S., Kumar, S., Ghimire, S. and Shrestha, U. (2009) Multiple Arterial Anomalies in Upper Limb. Kathmandu University Medical Journal, 27, 293-299.

[11] McCormack, L.J., Cauldwell, E.W. and Anson, B.J. (1953) Brachial and Antebrachial Arterial Patterns. The Journal of Surgery, Gynecology and Obstetrics, 96, 43-54.

[12] Kumar, H., Srijit, D. and Gaur, S. (2007) Entrapment of the Median Nerve and the Brachial Artery by the Lacertus Fibrosus. Archives of Medical Science, 3, 284-286.

[13] Rodrigues, V., Nayak, S., Nagabhooshana, S. and Vollala, R.V. (2008) Median Nerve and Brachial Artery Entrapment in the Tendinous Arch of Coracobrachialis Muscle. The International Journal of Acoustics and Vibration, 1, 28-29.

[14] Paval, J. (2008) A Rare Case of Possible Median Nerve Entrapment. Neuroanatomy, 5, 35-38.

[15] Mas, N., Pelin, C., Zagyapan, R. and Bahar, H. (2008) Unusual Relation of the Median Nerve with the Accessory Head of the Biceps Brachii Muscle: An Original Case Report. International Journal of Morphology, 24, 581-584.

[16] Cavolli, R., Eryilmaz, S. and Ozyurda, U. (2007) Report of the Anatomic Variation of the Brachial Artery in A Patient Undergoing Transradial Cardiac Catherization. Journal of Vascular Nursing, 25, 19-20. http://dx.doi.org/10.1016/j.jvn.2006.12.001 